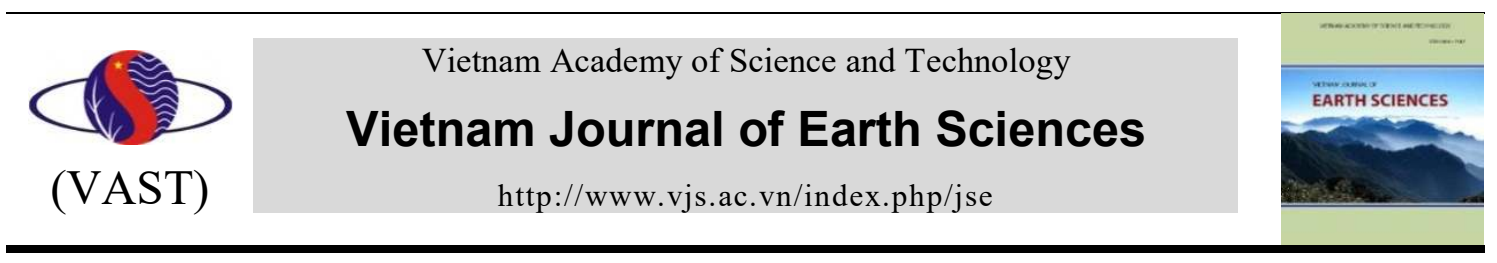

\title{
Seismic activity characteristics in the East Sea area
}

\author{
Vu Thi Hoan ${ }^{1}$,Ngo Thi Lu ${ }^{1,2}$, Rodkin M. V.3, Nguyen Quang4, Phan Thien Huong5 \\ ${ }^{1}$ Institute of Geophysics, (VAST), Hanoi. Vietnam \\ ${ }^{2}$ Graduate University of Science and Technology, (VAST), Hanoi. Vietnam \\ ${ }^{3}$ International Institute of Earthquakes Prediction Theory and Mathermatical Geophysics, RAS, Moscow \\ ${ }^{3}$ Vietnam Union of Geological Sciences \\ ${ }^{4}$ Hanoi University of Mining and Geology
}

Received 29 January 2018; Received in revised form 15 March 2018; Accepted 30 May 2018

\begin{abstract}
In this paper, seismic activity characteristics in the East Sea area was analyzed by authors on the base of the unified earthquake catalog (1900-2017), including 131505 events with magnitude $3 \leq \mathrm{Mw} \leq 8.4$. The seismic intensity in the East Sea during the period $1900-2017$ is characterized by the earthquake representative level Mw $=4.7$. The strong earthquake activity in the East Sea area clearly shows the regularity in each stage. In the period from 1900 to 2017, the East Sea area has four periods of strong earthquake activity, each stage is nearly 30 years with particular characteristics. The distribution of the maximum earthquake quantities by years has a cyclicity in all four periods. In each stage there are 1-2 strong earthquakes with $M_{\max } \geq 8.0$. The strong earthquakes with $\mathrm{M}_{\max } \geq 7.5$ have occurred by a repeatable rule of 3-5 years in all four stages. This allows the prediction of the maximum earthquake repeat cycle of $\mathrm{M}_{\max } \geq 7.5$ in the study area is 3-5 years. In other hand, the maximum magnitude values for the East Sea region has assessed by GEV method with several different predict periods (20, 40, 60, 80, 100 years), with predicted probability $80 \%$. We concluded that it is possible that earthquake have $\mathrm{M}_{\max }=8.7$ will occur in next 100 years.

Keywords: Seismic activity; macximum earthquake magnitude; earthquake catalog, the East Sea; Generalized Extreme Value distribution - GEV.
\end{abstract}

C2018 Vietnam Academy of Science and Technology

\section{Introduction}

Earthquake is one of the most serious disasters in Asia. Study of earthquake and seismotectonics in the mainland is interested recently by many workers (Duan et al, 2013). However, the study of the earthquake in the sea is limited due to lack of data and methodology. Based on the relation between the seismotectonics and geodynamic, the East Sea is a part of Southeast Asia. Southeast Asia is

${ }^{*}$ Corresponding author, Email: hoanvt84@gmail.com located at the boundary between the two major seismic activity belts associated with the two-main tectonic-destroying belts: the Pacific Earthquakes belt and the MediterraneanHymalaya belt. Consequently, South East Asia generally and the East Sea region particularly are influenced by the tectonic activities of these belts. The East Sea area is the transition zone between the Philippine Sea Plate in the east, the Eurasian Plate in the west, and the Australian Plate in the southeast. These plates move with different velocities. The Philippine sea plate moves from east to west 
at the rate of $50 \mathrm{~mm} / \mathrm{yr}$ (Yingchun Liu et al., 2007) or $55.6 \mathrm{~mm} / \mathrm{yr}$ (Le Huy Minh et al., 2014). The Eurasian plate move north-west nearly $10 \mathrm{~mm} / \mathrm{yr}$ (Bautista et al., 2001, Yingchun Liu et al., 2007, Le Huy Minh et al., 2014). And the Australian migration in the north-east direction moves at the speed of 6-7 $\mathrm{cm} / \mathrm{yr}$ (Phan Trong Trinh et al., 2011). These movements make the East Sea in danger of earthquakes and tsunamis. Therefore, the study about the characteristics of earthquake activities and assessing the maximum earthquake magnitude for this area are significantly important; it plays a critical role in forecasting earthquakes and tsunamis in the East Sea. There are various studies about these topics. We can mention to the earthquake zonation studies, recent basalts and features of the East Sea tsunami (Pham Van Thuc, 2001) or Pham Van Thuc and Nguyen Thi Kim Thanh (Pham Van Thuc and Nguyen Thi Kim Thanh, 2004). In the research in 2004, Pham Van Thuc and Nguyen Thi Kim Thanh built a zoning evaluation map with scale 1: 1000000 for the East Sea and coastal. It is said to be the first project which divides the East Sea into different tectonic-dynamic regions. The authors divided the study area which contains the earthquakes catalog collected from 1524 to 2002 into nine sub-regions with corresponding $\mathrm{M}_{\max }$ values. In this paper, the strongest earthquake zone is the North East Coast of the East Sea with $\mathrm{M}_{\max }=7.5$ and the weakest one is the western part of the East Sea with $\mathrm{M}_{\max }=3$ (Pham Van Thuc and Nguyen Thi Kim Thanh, 2004).

Moreover, the tectonic stress field in the East Sea was studied by Nguyen Van Luong, 2002, Nguyen Van Luong et al., 2003, 2008 $(a, b)$. It shows the suitability of geodynamic mechanisms on seismic fault systems. Specifically, there are the oblique reverses on the Manila subduction zone. Meanwhile, on the fault systems North East North and East Sea East, the most popular type of focal mechanism is strike-slip. In other works, the authors have concentrated on the assessment of earthquake risk like Pham Van Thuc et al., 2004; Nguyen Van Luong et al., 2003; Nguyen
Hong Phuong, 2001; Nguyen Hong Phuong et al., 2012, 2015.

There are more studies about the causes of earthquake-tsunami after the Sumatra tsunami in December 2004, (Bui Cong Que et al., 2010; Cao Dinh Trieu et al., 2008; Phan Trong Trinh, 2006; Phan Trong Trinh et al., 2010; Nguyen Dinh Xuyen et al., 2007; Cao Dinh Trieu et al., 2009; Vu Thanh Ca et al., 2008).

Vietnam and East Sea earthquake risk map was established in 2004 by Nguyen Hong Phuong (Nguyen Hong Phuong, 2004). In this study, the author used the software to filter the foreshocks and aftershocks, and adjusted the boundaries of the source regions according to the seismic data in the period of 114-2002. In the following years, Nguyen Hong Phuong and his co-authors have continued to study about the seismic source of this area. In these studies, the data included historical seismic data and machine seismic data. Tsunami source zones in the East Sea have been identified, within the Northern Manila Trench is the highest seismic risk with $\mathrm{M}_{\max }=8.7 \pm 0.93$ for 2658 years (Nguyen Hong Phuong et al., $2012,2015)$. This result is the same with result of another Chinese author using earthquake data from NEIC in the period 19002013 and Global CMT's catalog in the period 1963-2013 with $\mathrm{M}>5.0$ (Zhiguo $\mathrm{Xu}, 2015$ ). Meanwhile, a group of authors from the Nanyang Technological University in Singapore shown that the tsunami earthquake in this area could reach 9.0 (Megawati al., 2009). It is noticeable that these studies didn't show a specified duration for predicting $\mathrm{M}_{\max }$. The methodology of the Generalized Extreme Value Distribution (GEV) can solve this problem. This probabilistic method has been developed by Pisarenko and his colleagues to evaluate the maximum earthquake magnitude for many catalogs such as the Harvard earthquake list (Pisarenko et al., 2008, 2014), the Japanese earthquake catalog (Pisarenko et al., 2010),...

Thus, in general, it has been shown that the East Sea area has the potentially high seismic 
risk. However, historical earthquake data and machine data were used and the magnitudes have not been unified. In addition, predicting $\mathrm{M}_{\max }$ does not have a specified duration. In this paper, the characteristics of earthquake activity in the East Sea area will be studied on the basis of the unified earthquake catalog for the period 1900-2017, and $\mathrm{M}_{\max }$ will be estimated by GEV method.

\section{Data and Methodology}

\subsection{Data}

The study area is limited by the coordinates $\varphi=5^{\circ} \mathrm{S} \div 30^{\circ} \mathrm{N} ; \lambda=100^{\circ} \div 127^{\circ} \mathrm{E}$. However, some foreshocks and aftershocks in the East Sea region can belong to main shocks which are not in this region. Therefore, to ensure the independence of events in the study area, it needs to extend the area for collecting seismic data. The area extended is limited by the coordinates $\varphi=11.2^{\circ} \mathrm{S}-35.5^{\circ} \mathrm{N} ; \lambda=92.5^{\circ} \mathrm{E}$ $132^{\circ} \mathrm{E}$.

Earthquake data were collected and adjusted from various sources: International Seismological Center (ISC), U.S. Geological Survey (USGS), Regional Integrated MultiHazard Early Warning System for Africa and Asia (RIMES). The earthquake catalog of the East Sea and neighboring for the period 1900 -2017 has 316516 earthquakes with magnitude $M \geq 3.0$. It should be noted that there is some kind of magnitude scales: local magnitude $\left(\mathrm{M}_{\mathrm{L}}\right)$, surface-wave magnitude $\left(\mathrm{M}_{\mathrm{S}}\right)$, body-wave magnitude $\left(\mathrm{m}_{\mathrm{b}}\right)$, moment magnitude $\left(\mathrm{M}_{\mathrm{w}}\right)$. Therefore, it is necessary to unify magnitude scale. On the other hand, $\mathrm{M}_{\mathrm{L}}, \mathrm{M}_{\mathrm{S}}$, $m_{b}$ have saturated value which is almost the same value of strong earthquakes. In addition, the moment magnitude is used the most common to estimate the seismic hazard and warn tsunami. Therefore, in this paper, the $\mathrm{M}_{\mathrm{w}}$ is only scale used. The others will be converted to $\mathrm{M}_{\mathrm{w}}$ by practical functions.

In the extensive region, period 1900 2017, we collected 377784 events with $\mathrm{Mw}$ in the range from 3 to 9.1. The spacetime window method which proposed in (Ngo and Tran, 2013) was used to separate the groups of foreshocks and aftershock from the abovementioned earthquake. The independence catalog of the East Sea region and neighboring area includes 202544 events with magnitude $\mathrm{Mw}(3 \leq \mathrm{Mw} \leq 9.1)$ in which has 131505 events with magnitude $3 \leq \mathrm{Mw} \leq 8.4$ belong to the East Sea region. This is a list of earthquakes that will be used in the calculations below.

\subsection{Methodology}

The distribution function generalized extreme value is defined as follows (Pisarenko, 2007, 2008, 2010):

$\operatorname{GEV}(\mathrm{x} \mid \sigma, \mu, \zeta)=\left\{\begin{array}{cc}\exp \left(-\left[1+\frac{\zeta}{\sigma} \cdot(\mathrm{x}-\mu)\right]^{-\frac{1}{\zeta}, \zeta<0 ; \sigma>0 ;} x \leq \mu-\sigma / \zeta, \zeta \neq 0\right. \\ \exp \left(-\exp \left[-\frac{\mathrm{x}-\mu}{\sigma}\right]\right), \quad \zeta=0\end{array}\right.$

Where $\mathrm{x}$ is variable representing the magnitude earthquake value, $\sigma$ is the scale parameter, $\mu$ is the location parameter, $\zeta$ is the form parameter.

To determine the GEV function, we need to identify 3 parameters $\zeta, \sigma, \mu$ in formula (1). These parameters $\zeta, \sigma, \mu$ are determined in each period $\mathrm{T}$, solving by the equations below:

$\frac{1}{n} \sum_{k=1}^{n} x_{k}=\mu-\frac{\sigma}{\zeta}+\frac{\sigma}{\zeta} \Gamma(1-\zeta)=M 1$ 
With $\Gamma(\mathrm{x})$ is the Gamma function: $\Gamma(\mathrm{t})=$ $\int_{0}^{\infty} x^{t-1} e^{-x} d x, \mathrm{n}$ is the number of earthquakes in each T-intervals, $x_{k}$ is magnitude of $k^{\text {th }}$ earthquake.

It is important to determine T-intervals fit with each catalog because T-intervals influence the values of the three parameters $\zeta, \sigma, \mu$ of the GEV function. To find T-intervals, we determine the density Poisson distribution $(\lambda)$ of the magnitude values:

$\lambda=\frac{N}{t}$, where $\mathrm{N}$ is the number of independent earthquakes, $t$ is the time between the first event and the last event.

The $\mathrm{T}$ - intervals value (days) must satisfy three conditions:

(a) All T-intervals is non-empty.

(b) Value $1 / \lambda T \rightarrow 0$ (with $\lambda$ is the frequency earthquakes with magnitude $M \geq m$ ).

(c) Value of parameter $\zeta$ is enough stable to determine the GEV function.

Choose an interval of values $\left(\mathrm{T}_{\mathrm{L}} ; \mathrm{T}_{\mathrm{H}}\right)$ for time interval durations $\mathrm{T}$, for which the cata$\log$ still contains a sufficient number of $\mathrm{T}$ intervals;

Choose in this interval $\left(\mathrm{T}_{\mathrm{L}} ; \mathrm{T}_{\mathrm{H}}\right)$ a finite set of $u$ time-interval durations $\mathrm{T}\left(\mathrm{T}_{\mathrm{L}} \leq \mathrm{T}_{1}<\mathrm{T}_{2}<\ldots<\mathrm{T}_{\mathrm{u}} \leq \mathrm{T}_{\mathrm{H}}\right)$;

The GEV parameters are estimated by the equations (2-4) for each of the u time - interval durations $\mathrm{T}$, which yields the following set of parameters:

$$
\begin{aligned}
& \zeta\left(\mathrm{T}_{1}\right), \zeta\left(\mathrm{T}_{2}\right), \ldots, \zeta\left(\mathrm{T}_{\mathrm{u}}\right) ; \\
& \sigma\left(\mathrm{T}_{1}\right), \sigma\left(\mathrm{T}_{2}\right), \ldots, \sigma\left(\mathrm{T}_{\mathrm{u}}\right) ; \\
& \mu\left(\mathrm{T}_{1}\right), \mu\left(\mathrm{T}_{2}\right), \ldots, \mu\left(\mathrm{T}_{\mathrm{u}}\right) ;
\end{aligned}
$$

To estimate the average values $\zeta, \sigma, \mu$ of the GEV parameters $\zeta, \sigma, \mu$

The $\tau$ is the predict period (from the time of the earthquake event was chosen as supporting event). The parameters $\zeta, \sigma, \mu$ are represented as the functions of $\tau$ by the formulas (5-7) below:

$$
\begin{aligned}
& \zeta(\tau)=\zeta(T) \\
& \sigma(\tau)=\sigma(T) \cdot(\tau / T)^{\xi} \\
& \mu(\tau)=\mu(T)+(\sigma(T) / \xi) \cdot\left((\tau / T)^{\xi}-1\right)
\end{aligned}
$$

The quantile in this period is:

$$
\mathrm{Q}_{\mathrm{q}}(\tau)=\mathrm{h}+(\mathrm{s} / \xi) \cdot\left(\mathrm{a} \cdot(\lambda \tau)^{\xi}-1\right)
$$

Inside:

$\mathrm{a}=(\log (1 / \mathrm{q}))^{-\xi}$,

$\mathrm{h}=\mu+(\sigma / \xi) \cdot\left((\lambda \mathrm{T})^{-\xi}-1\right.$;

$\mathrm{s}=\sigma .(\lambda \mathrm{T})^{-\xi}$.

When $\tau \rightarrow \infty$ then $\mathrm{Q}_{\mathrm{q}}(\tau)=\mathrm{M}_{\max }(\tau) \rightarrow \mathrm{M}_{\max }$ : $M_{\text {max }}^{\text {predict }} \underset{\tau \rightarrow \infty}{=} \lim _{q} Q_{q}(\tau)$

Thus, after finding the appropriate $\mathrm{T}$ intervals, in each time period T-intervals the parameters $\zeta, \sigma, \mu$ would be determined. From that we will determine the GEV function, decile point value of $\mathrm{Q}_{\mathrm{q}}(\tau)$, and assess the value $\mathrm{M}_{\max }$.

In order to estimate the Mean Square Error (MSE) of these estimates, we use formulas (Gumbel, 1958):

$$
\begin{aligned}
\operatorname{MES}_{\zeta} & =\left[(1 / n) \sum_{j=1}^{n}\left(\zeta_{\mathrm{j}}-\bar{\zeta}\right)^{2}\right]^{1 / 2} \\
M E S_{\sigma} & =\left[(1 / n) \sum_{j=1}^{n}\left(\sigma_{\mathrm{j}}-\bar{\sigma}\right)^{2}\right]^{1 / 2} \\
\operatorname{MES}_{\mu} & =\left[(1 / n) \sum_{j=1}^{n}\left(\mu_{\mathrm{j}}-\bar{\mu}\right)^{2}\right]^{1 / 2}
\end{aligned}
$$

\section{Characteristic of earthquake activity in the East Sea}

Based on the earthquake catalog with 131505 independent events, this study focused on the seismic activity in the East Sea.

The Gutenberg - Richter magnitudefrequency relationship.

Base on Table 1, the Gutenberg-Richter relation between the number of earthquakes with magnitudes written for the natural logarithm is:

$$
\mathrm{LgN}=8.89-0.91 \mathrm{M}_{\mathrm{w}}
$$

With correlation coefficient $\mathrm{R}=0.99$

Where $\mathrm{N}$ is number of earthquakes of magnitude $\mathrm{M}_{\mathrm{w}}$ in certain range (Table 1). 
Vietnam Journal of Earth Sciences, 40(3), 240-252

Table 1. The number of earthquakes depened on magnitude value

\begin{tabular}{|c|c|c|c|c|c|}
\hline $\mathrm{M}_{\mathrm{w}}$ & $\mathrm{N}$ & $\log (\mathrm{N})$ & $\mathrm{M}_{\mathrm{w}}$ & $\mathrm{N}$ & $\log (\mathrm{N})$ \\
\hline $3-3.4$ & 11297 & 4.05296313 & $6-6.4$ & 909 & 2.95856 \\
\hline $3.5-3.9$ & 24373 & 4.38690899 & $6.5-6,9$ & 327 & 2.51455 \\
\hline $4-4.4$ & 60435 & 4.78128853 & $7-7.4$ & 139 & 2.14301 \\
\hline $4.5-4.9$ & 23336 & 4.36802642 & $7.5-7.9$ & 61 & 1.78533 \\
\hline $5-5.4$ & 8357 & 3.9220504 & $8-8.4$ & 10 & 1 \\
\hline $5.5-5.9$ & 2261 & 3.35430056 & & & \\
\hline
\end{tabular}

Table 1 and Figure 1 show that the East Sea has threshold earthquake magnitude $\mathrm{M}=4.7$.

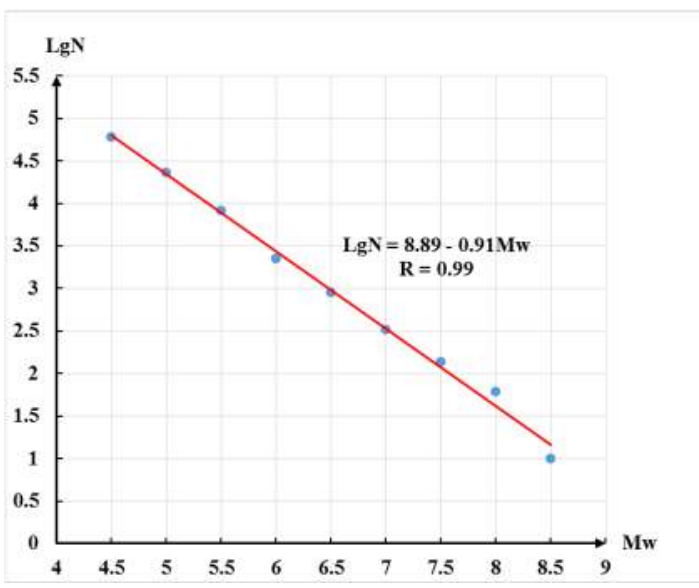

Figure 1. The Gutenberg-Richter frequency-magnitude diagrams (1900 - 2017)

Distribution of earthquake number with the depth

Base on the collected database, we analyze the distribution of earthquake number with the depth. The results are performed in Figure 2 and Table 2 .

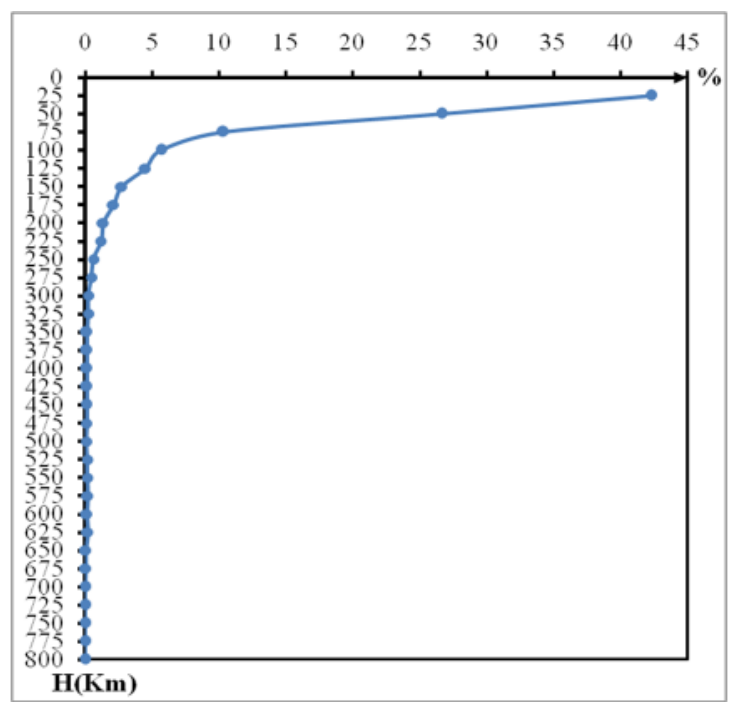

Figure 2. Distribution of earthquake number depended on depth

Table 2. Distribution of earthquake number with the depth

\begin{tabular}{|c|c|c|c|c|c|c|c|c|}
\hline $\mathrm{H}(\mathrm{Km})$ & 50 & 100 & 150 & 200 & 250 & 300 & 350 & 400 \\
\hline $\mathrm{N}$ & 90650 & 21055 & 9512 & 4574 & 2358 & 858 & 451 & 296 \\
\hline$\%$ & 59.1 & 59.1 & 13.7 & 6.2 & 3 & 1.5 & 0.6 & 0.3 \\
\hline $\mathrm{H}(\mathrm{Km})$ & 450 & 500 & 550 & 600 & 650 & 700 & 750 & 800 \\
\hline $\mathrm{N}$ & 292 & 242 & 410 & 435 & 322 & 46 & 1 & 3 \\
\hline$\%$ & 0.2 & 0.2 & 0.3 & 0.3 & 0.2 & 0 & 0 & 0 \\
\hline
\end{tabular}

Table 2 and Figure 2 show that the majority of earthquakes in the East Sea area occur in the depth of $0-75 \mathrm{~km}(79.27 \%)$ equivalent to the crust of the Earth. This result is nearly similar to the previous study on the Northern Luzon subduction model where the authors used shorter period data 1619-1997 (Bautista et al., 2001). This proves the objectivity and reliability of this work.
Distribution of earthquake epicenters in the period 1900-2017

Based on the earthquake catalog and a regional geodynamic scheme in accordance with the structure, we have established an earthquake epicenter distribution map of the East Sea with $\mathrm{Mw} \geq 5.0$ (Figure 3). Figure 3 shows that the majority of earthquake epicenters in East Sea region are distributed around Philip- 
pine. Noticeably, throughout the study period (1900-2017), there were eight the strongest earthquakes with the magnitude $\mathrm{M}_{\mathrm{w}} \geq 8.0$, of which the strongest with $M=8.4$ occurred on the $12^{\text {th }}$ September 2007 at coordinates $\varphi=-$ $4.4^{\circ} \mathrm{N}, \quad \lambda=101.4^{\circ} \mathrm{E}$ (Table 3 ). Most of them located in the eastern and southeastern part of the study area (Figure 3). These results are quite similar to the results obtained by Zhiguo $\mathrm{Xu}$ using earthquake catalog's NEIC from 1900 to 2013, and the earthquake catalog's Global CMT from 1963 to 2013 (Zhiguo Xu, 2015) or by Hsu using the data period 19732010 with $M_{w}$ 4.6-7.7 (Hsu et al., 2012).

Table 3. The strongest earthquakes catalog $\left(M_{w} \geq 8.0\right)$ in the East Sea from 1900 to 2017

\begin{tabular}{|c|c|c|c|c|c|c|c|c|c|c|}
\hline No. & Year & Month & Day & Hour & Minute & Second & Latitude & Longitude & Depth & $\mathrm{Mw}$ \\
\hline 1 & 1910 & 4 & 12 & 0 & 22 & 24 & 25.9 & 124 & 235 & 8.1 \\
\hline 2 & 1918 & 8 & 15 & 12 & 18 & 21 & 6 & 124.4 & 20 & 8.3 \\
\hline 3 & 1920 & 6 & 5 & 4 & 21 & 35 & 23.7 & 122 & 20 & 8.1 \\
\hline 4 & 1924 & 4 & 14 & 16 & 20 & 36 & 6.7 & 126 & 15 & 8 \\
\hline 5 & 1939 & 12 & 21 & 21 & 0 & 31 & -0.1 & 122.5 & 35 & 8.1 \\
\hline 6 & 1965 & 1 & 24 & 0 & 11 & 17 & -2.6 & 126 & 20 & 8.2 \\
\hline 7 & 1972 & 12 & 2 & 0 & 19 & 52 & 6.4 & 126.6 & 60 & 8 \\
\hline 8 & 2007 & 9 & 12 & 11 & 10 & 26 & -4.4 & 101.4 & 34 & 8.4 \\
\hline
\end{tabular}

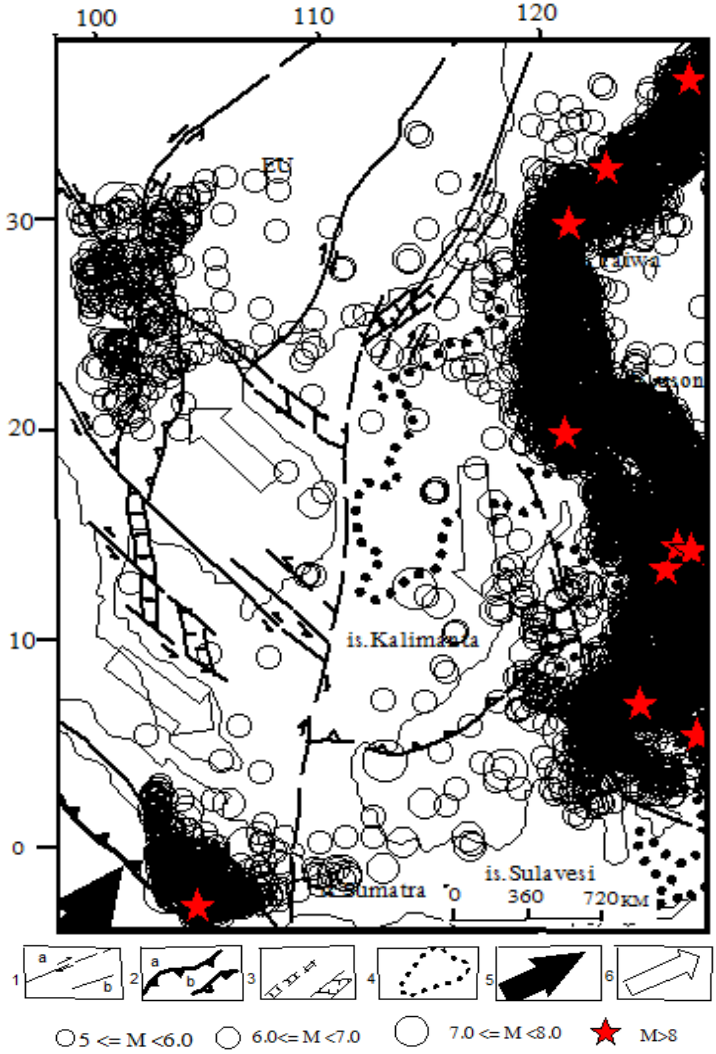

Figure 3. Earthquake distribution in East Sea and its adjacent regions 1900-2017 ( $\mathrm{M} \geq 5.0)$ $\leftarrow$ Note: 1, 2 - major faults, active in Late Cenozoic: 1 - transverse ( $\mathrm{a}$ - determine and assume, $\mathrm{b}$ - fault the planet); 2 - Large subsidence zone (a - Benhiop zone,

b- Other subsidence zone); 3- Expansion structures: a - Deep coastal trenches, b - Sediment tanks within the continental limits and continental shelf; 4 - Deep-water seabed belt; 5, 6 - Moving vectors: 5 - of the main lithosphere, 6 - of the eastern part of the European - Asian plate. Main arrays are marked by the letters: EU - Europe - Asia, P - Pacific, PH - Philippine Plates. The Roman numerals denote the blocks: I - Tibet - Hymalaya, II - Southeast China, III - Indochina,

VI - East Sea, V - Middle East, VI - Kalimantan - Iava

The time - magnitude distribution of the catalog is presented in Table 4 and in Figure 4. It illustrated that before 1964, the number of earthquakes was not recorded much (few dozen times/year). Later in the year of 1964 1983, the number of earthquakes raised to hundreds and since 1984 reached thousands; it reached the peak of 8748 earthquakes in 2012. A part of the phenomenon comes from the seismic network that was sparse and the sensitivity of the seismograph which was not high enough to record weak and distant earthquakes. Hence, considering the rule of strong earthquake activity, we need to pay special attention to the earthquake threshold. 
Vietnam Journal of Earth Sciences, 40(3), 240-252

Earthquake procedure time line in the East Sea period 1900-2017

With $\mathrm{N}$ is the number of earthquakes annually.
The distribution of maximum earthquake magnitude by year

The annual maximum earthquake magnitude is shown in Table 5 and Figure 5.

Table 4. The time - magnitude distribution of the East Sea's catalog ( $3 \leq \mathrm{Mw} \leq 8.4)$ from 1900 to 2017

\begin{tabular}{|c|c|c|c|c|c|c|c|c|c|}
\hline Year & $\mathrm{N}$ & Year & $\mathrm{N}$ & Year & $\mathrm{N}$ & Year & $\mathrm{N}$ & Year & $\mathrm{N}$ \\
\hline 1900 & 2 & 1924 & 9 & 1948 & 7 & 1972 & 377 & 1996 & 4133 \\
\hline 1901 & 3 & 1925 & 14 & 1949 & 3 & 1973 & 405 & 1997 & 3715 \\
\hline 1902 & 2 & 1926 & 16 & 1950 & 18 & 1974 & 358 & 1998 & 4567 \\
\hline 1903 & 1 & 1927 & 9 & 1951 & 45 & 1975 & 565 & 1999 & 5941 \\
\hline 1904 & 1 & 1928 & 8 & 1952 & 14 & 1976 & 618 & 2000 & 5421 \\
\hline 1905 & 1 & 1929 & 15 & 1953 & 9 & 1977 & 604 & 2001 & 5421 \\
\hline 1906 & 5 & 1930 & 8 & 1954 & 17 & 1978 & 648 & 2002 & 6058 \\
\hline 1907 & 5 & 1931 & 18 & 1955 & 27 & 1979 & 668 & 2003 & 5399 \\
\hline 1908 & 4 & 1932 & 30 & 1956 & 19 & 1980 & 956 & 2004 & 5461 \\
\hline 1909 & 5 & 1933 & 17 & 1957 & 25 & 1981 & 691 & 2005 & 5834 \\
\hline 1910 & 7 & 1934 & 21 & 1958 & 28 & 1982 & 912 & 2006 & 6533 \\
\hline 1911 & 2 & 1935 & 22 & 1959 & 22 & 1983 & 911 & 2007 & 8188 \\
\hline 1912 & 3 & 1936 & 20 & 1960 & 17 & 1984 & 1125 & 2008 & 7402 \\
\hline 1913 & 3 & 1937 & 10 & 1961 & 20 & 1985 & 2059 & 2009 & 8307 \\
\hline 1914 & 2 & 1938 & 16 & 1962 & 26 & 1986 & 2800 & 2010 & 6990 \\
\hline 1915 & 5 & 1939 & 7 & 1963 & 29 & 1987 & 960 & 2011 & 6749 \\
\hline 1916 & 1 & 1940 & 10 & 1964 & 228 & 1988 & 914 & 2012 & 8748 \\
\hline 1917 & 1 & 1941 & 22 & 1965 & 247 & 1989 & 1044 & 2013 & 7713 \\
\hline 1918 & 8 & 1942 & 7 & 1966 & 289 & 1990 & 1597 & 2014 & 8360 \\
\hline 1919 & 8 & 1943 & 7 & 1967 & 244 & 1991 & 1639 & 2015 & 8093 \\
\hline 1920 & 3 & 1944 & 3 & 1968 & 349 & 1992 & 1750 & 2016 & 3684 \\
\hline 1921 & 4 & 1945 & 4 & 1969 & 303 & 1993 & 2303 & 2017 & 3388 \\
\hline 1922 & 5 & 1946 & 4 & 1970 & 442 & 1994 & 2114 & & \\
\hline 1923 & 8 & 1947 & 3 & 1971 & 199 & 1995 & 3173 & & \\
\hline
\end{tabular}

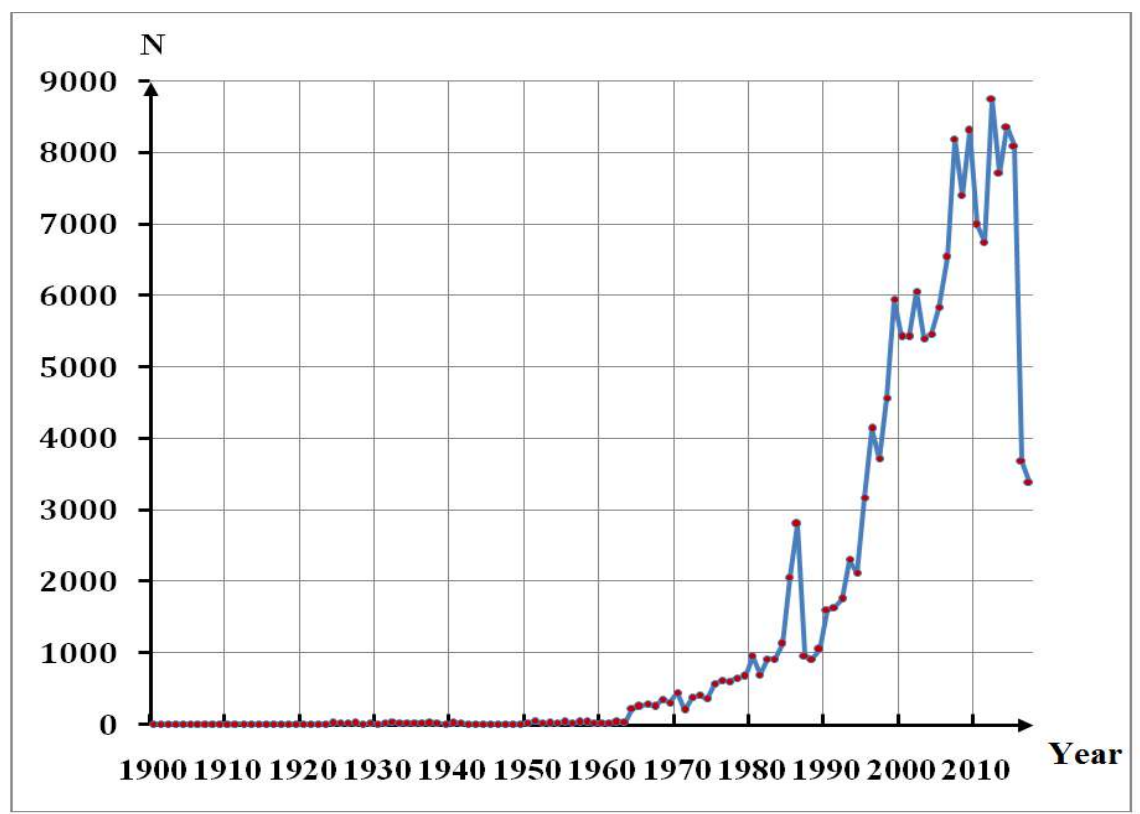

Figure 4. Earthquake procedure time line in the East Sea period 1900-2017 
Vu Thi Hoan, et al./Vietnam Journal of Earth Sciences 40 (2018)

Table 5. The annual maximum earthquake magnitude

\begin{tabular}{|c|c|c|c|c|c|}
\hline Year & $\mathrm{M}_{\max }$ & Year & $\mathrm{M}_{\max }$ & Year & $\mathrm{M}_{\max }$ \\
\hline 1900 & 7 & 1940 & 6.9 & 1980 & 6.8 \\
\hline 1901 & 7.5 & 1941 & 7.5 & 1981 & 6.6 \\
\hline 1902 & 7 & 1942 & 7.5 & 1982 & 7.1 \\
\hline 1903 & 7 & 1943 & 7.8 & 1983 & 6.9 \\
\hline 1904 & 7.8 & 1944 & 6.8 & 1984 & 7.5 \\
\hline 1905 & 7.8 & 1945 & 6.8 & 1985 & 7 \\
\hline 1906 & 7.3 & 1946 & 6.8 & 1986 & 7.5 \\
\hline 1907 & 7.6 & 1947 & 7.4 & 1987 & 6.9 \\
\hline 1908 & 7.2 & 1948 & 7.8 & 1988 & 7.3 \\
\hline 1909 & 7.6 & 1949 & 7.4 & 1989 & 7.6 \\
\hline 1910 & 8.1 & 1950 & 7.3 & 1990 & 7.8 \\
\hline 1911 & 8.2 & 1951 & 7.8 & 1991 & 7.5 \\
\hline 1912 & 7.5 & 1952 & 7.4 & 1992 & 7.3 \\
\hline 1913 & 7.8 & 1953 & 6.9 & 1993 & 7 \\
\hline 1914 & 7.6 & 1954 & 6.7 & 1994 & 7.9 \\
\hline 1915 & 7.4 & 1955 & 7.5 & 1995 & 7.2 \\
\hline 1916 & 7.2 & 1956 & 6.7 & 1996 & 7.9 \\
\hline 1917 & 7 & 1957 & 7.3 & 1997 & 7 \\
\hline 1918 & 8.3 & 1958 & 7.2 & 1998 & 7.7 \\
\hline 1919 & 7.1 & 1959 & 7.5 & 1999 & 7.7 \\
\hline 1920 & 8.2 & 1960 & 6.6 & 2000 & 7.9 \\
\hline 1921 & 7.5 & 1961 & 6.9 & 2001 & 7.5 \\
\hline 1922 & 7.5 & 1962 & 6.5 & 2002 & 7.5 \\
\hline 1923 & 7.4 & 1963 & 7.2 & 2003 & 7 \\
\hline 1924 & 8 & 1964 & 7.4 & 2004 & 7.3 \\
\hline 1925 & 7.3 & 1965 & 8.2 & 2005 & 7.1 \\
\hline 1926 & 6.8 & 1966 & 7.7 & 2006 & 7.1 \\
\hline 1927 & 7 & 1967 & 6.8 & 2007 & 8.4 \\
\hline 1928 & 7.5 & 1968 & 7.6 & 2008 & 7.4 \\
\hline 1929 & 7.3 & 1969 & 7.6 & 2009 & 7.2 \\
\hline 1930 & 6.9 & 1970 & 7.4 & 2010 & 7.8 \\
\hline 1931 & 6.8 & 1971 & 7 & 2011 & 7.4 \\
\hline 1932 & 7.8 & 1972 & 8 & 2012 & 7.6 \\
\hline 1933 & 6.8 & 1973 & 7 & 2013 & 7.3 \\
\hline 1934 & 7.6 & 1974 & 6.8 & 2014 & 7.7 \\
\hline 1935 & 7 & 1975 & 7.2 & 2015 & 8 \\
\hline 1936 & 7.8 & 1976 & 7.9 & 2016 & 7.9 \\
\hline 1937 & 7.6 & 1977 & 7 & 2017 & 7.3 \\
\hline 1938 & 7.7 & 1978 & 7.4 & & \\
\hline 1939 & 8.1 & 1979 & 7.1 & & \\
\hline
\end{tabular}

With $\mathrm{M}_{\max }$ as the maximum earthquake magnitude in the year, Figure 5 shows the cyclical nature of the strong earthquake activity at each stage. It is possible to divide the study period into 4 stages, each stage lasting nearly 30 years (from 1900 to 2017). Each stage has particular characteristics shown below:

Stage 1: From 1900 to 1927, it was characterized by the majority of $\mathrm{M}_{\max } \geq 8.0$ and the minimum were above 7.0.
Stage 2: From 1927 to 1960 with the majority of $\mathrm{M}_{\max } \geq 7.5$, while the minimum are 6.7 to 7.0 .

Stage 3: From 1960 to 1987 was characterized by the majority of $\mathrm{M}_{\max } \geq 7.5$, with some points below 7.5 , the minimum points are 6.5 -7.0 .

Stage 4: From 1987 to 2013 with most of the $\mathrm{M}_{\max }$ in the range of 7.0-7.8. At the end of this period, there was 8.4 in the year 2007 .

Figure 5 shows that the maximum number of earthquakes is seasonal in all four stages (Figure 5). In each phase, there are 1 to 2 max with $\mathrm{M}_{\max } \geq 8.0$. Each 3-5 years, there is one earthquake with magnitude 7.5 . This allows forecasting the maximum earthquake repeat cycle of $\mathrm{M}_{\max } \geq 7.5$ in the study area of 3-5 years.

From the increasing trend of the graph, we can see a new cycle with a maximum earthquake magnitude.

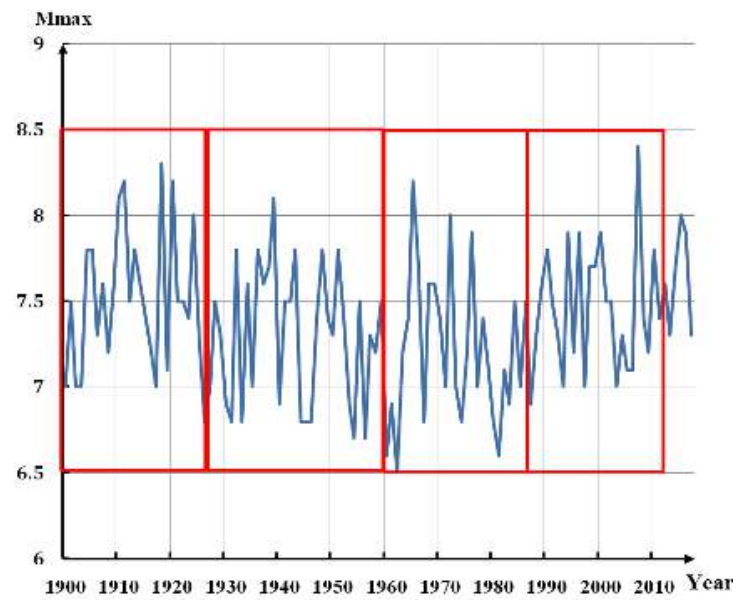

Figure 5. The distribution of maximum earthquake magnitude by year

\section{Results of estimating $M_{\max }$ by the gev method for the East Sea region}

To assess the maximum earthquake magnitude in the East Sea region, the used of magnitude values must be greater than or equal to the selected threshold value. This threshold value must greater than the earthquake magnitude which represent for catalog of the study 
area and it is sufficiently reliable in calculating parameters of GEV function. Accordingly, the threshold magnitude value was chosen $\mathrm{M}^{*}$ $=5.0$.

In order to ensure the reliability of results, the used data should be continuous. Analysis shows that it is continuous since 1917 , so we chose the period from 1917 to 2017 for estimating $\mathrm{M}_{\max }$. There are 12006 earthquakes with $\mathrm{M} \geq 5.0$ in this period.

In next section, we present the calculation results for the given data.

Step 1: Calculate the density Poisson distribution $(\lambda)$

The period from $30 / 7 / 1917 \quad\left(t_{1}\right)$ to $8 / 12 / 2017\left(t_{n}\right)$ is used with the daily unit. The total is 36655 days.
Density Poisson distribution is calculated as follows:

$$
\lambda=\mathrm{N} / \mathrm{t}=12006 / 36655=0,33
$$

Step 2: Select the jump (T)

The longest time of two events in the cata$\log$ is 291 days (from 11/11/1921 to 29/8/1922). Therefore, to satisfy the condition (a) above, the greater value of T-intervals is 291 days. The T-intervals in the corresponding product $\lambda \mathrm{T}$ are the following:

In principle above, the closer values to the value " 0 " $(1 / \lambda \mathrm{T})$ are, the better T-intervals are. From Table 6 , the greater T-intervals are, the smaller values of $1 / \lambda \mathrm{T}$ are. However, to satisfy the condition (c), Figure 6 shows an approximate "stabilization" of the $\zeta$ - estimates with $\mathrm{T}$ in range 300-350 days. Therefore, the value of $\mathrm{T}$-interval is 350 days.

Table 6. Table of T, $\lambda \mathrm{T}, 1 / \lambda \mathrm{T}$

\begin{tabular}{|c|c|c|c|c|c|c|c|c|}
\hline $\mathrm{T}$ (days) & 290 & 295 & 300 & 305 & 310 & 315 & 320 & 325 \\
\hline$\lambda \mathrm{T}$ & 95 & 97 & 98 & 100 & 102 & 103 & 105 & 106 \\
\hline $1 / \lambda \mathrm{T}$ & 0.0105 & 0.0103 & 0.0102 & 0.0100 & 0.0098 & 0.0097 & 0.0095 & 0.0094 \\
\hline $\mathrm{T}$ (days) & 330 & 335 & 340 & 345 & 350 & 355 & 360 & 365 \\
\hline$\lambda \mathrm{T}$ & 108 & 110 & 111 & 113 & 115 & 116 & 118 & 120 \\
\hline $1 / \lambda \mathrm{T}$ & 0.0093 & 0.0091 & 0.0090 & 0.0088 & 0.0087 & 0.0086 & 0.0085 & 0.0083 \\
\hline
\end{tabular}

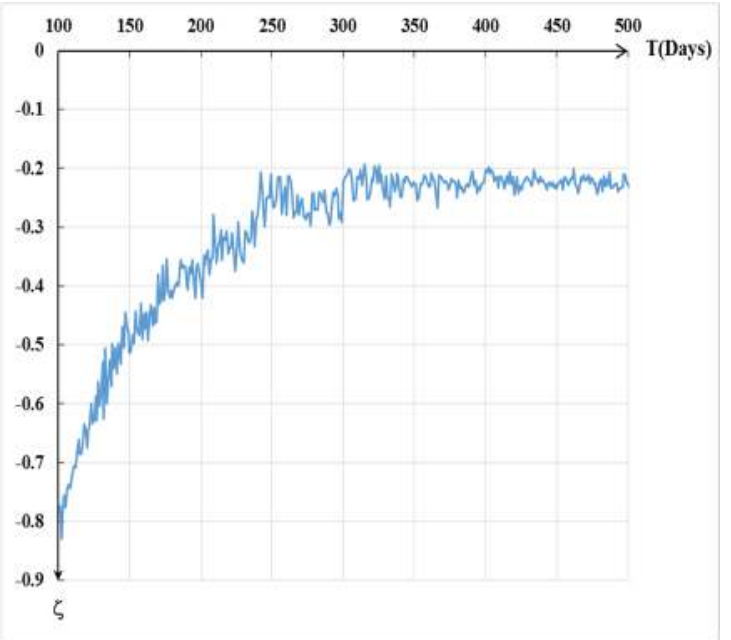

Figure 6. Graph the function $\zeta(\mathrm{T})$

Step 3: Determine the parameters $\zeta, \sigma, \mu$

With $\mathrm{T}=350$ days, then the number of $\mathrm{T}$ intervals is: $\mathrm{n}=$ interger $\frac{t_{n-t_{1}}}{T}=$ interger $\frac{36655}{350}=104$

We need to solve 104 systems of equations (2-4) to receive 104 sets of the three parameters $\zeta, \mathrm{s}, \mathrm{m}$. Taking the average of these three parameters in turn gives us the value of the parameters:

$\zeta=-0.23 ; \sigma=0.46 ; \mu=6.23$.

There are results: 0.21 .

$\operatorname{MSE}(\zeta)=0.05 ; \operatorname{MSE}(\mathrm{s})=0.06 ; \operatorname{MSE}(\mathrm{m})=$

Therefore, the parameters are:

$\zeta=-0.23 \pm 0.05 ; \mathrm{s}=0.46 \pm 0.06 ; \mathrm{m}=6.23 \pm$ 0.21 .

Step 4: Determine predicted $M_{\max }$

In use of earthquake catalog, the last strongest earthquake, which has occurred on January $10^{\text {th }} 2017$ with magnitude $M=7.3$ at latitude $\varphi=4.5^{\circ} \mathrm{N}$ and longitude $\lambda=122.6^{\circ} \mathrm{E}$. 
So we have chosen this event as supporting event.

$$
M_{\text {max }}^{\text {predict }}=\lim _{\tau \rightarrow \infty} Q_{q}(\tau)
$$

Using the results of the previous sections, we get the graph of the function $\mathrm{Q}_{\mathrm{q}}(\tau)$ in Figure 7 and its value in Table 7, with probability of $80 \%$.

Table 7. The values of $\mathrm{Q}_{0,8}(\tau)$ at the different $\tau$

\begin{tabular}{llllll}
\hline$\tau$ (year) & 20 & 40 & 60 & 80 & 100 \\
& $2017-$ & $2017-$ & $2017-$ & $2017-$ & $2017-$ \\
Period & 2037 & 2057 & 2077 & 2097 & 2117 \\
$\mathrm{Q}_{0,8}(\tau)$ & 8.25 & 8.50 & 8.6 & 8.65 & 8.7 \\
\hline
\end{tabular}

According to the Figure 7 and Table 7 above, we have $\mathrm{Q}_{0,8}(20)=8.25$. It means the prediction of $\mathrm{M}_{\max }$ is $\mathrm{M}_{\max }=8,25$ in the next 20 years from the supporting event.

When $\tau$ proceeds to infinity (since the value of 100 years), graph of the function $\mathrm{Q}_{0,8}(\tau)$ is almost unchanged (Figure 7). It means that the $M_{\max }$ predicted the value for the East Sea region is $\mathrm{M}_{\max }=8.7$ with probability $80 \%$.

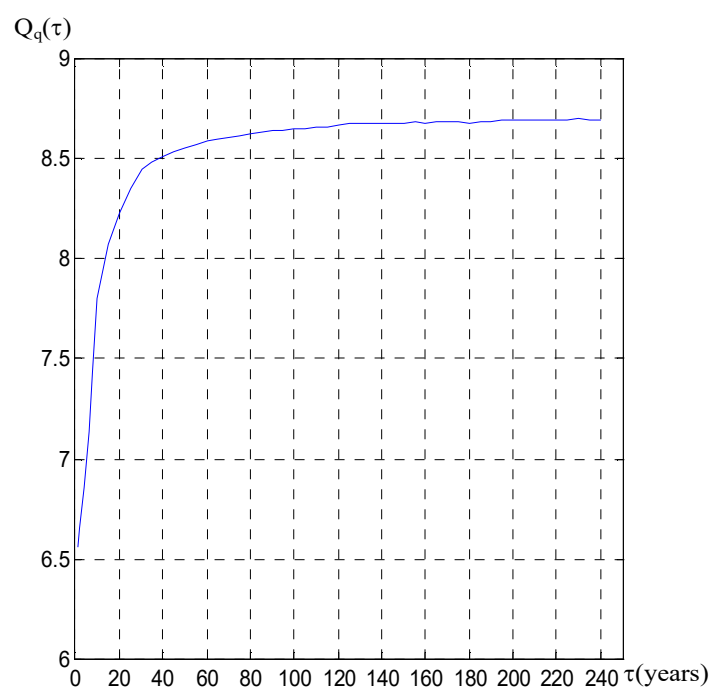

Figure 7. Graph of the function $\mathrm{Q}_{\mathrm{q}}(\tau)$ with $\mathrm{q}=0.8$ for the East Sea region $(M \geq 5,0)$ period 1917-2017

\section{Discussions}

Comparing the results obtained in this work with a series of previous research results of different authors in the East Sea region (Pham Van Thuc, 2001, Pham Van Thuc et al., 2004; Nguyen Van Luong et al., 2012; Zhiguo $\mathrm{Xu}, 2015)$, the East Sea is considered to be a high risk area for earthquakes, especially the possibility of strong earthquakes from the east of the study area along the Manila Trench. The maximum earthquake magnitude in the area is estimated at $\mathrm{M}_{\max } \geq 7.5$.

From the results of calculating the maximum earthquake magnitude $\mathrm{M}_{\max }$ above, we see that when using the universal value distribution function GEV, the result will depend on the factors such as the completeness and uniformity of the set: How to select the $\mathrm{T}$ jump, and how to select the magnitude earthquake threshold value. Because of the method of using the GEV predictive function, $\mathrm{M}_{\max }$ is one of the probability methods, so its results are consistent with the predicted results by other probabilistic methods such as the maximum rational method by Nguyen. Hong Phuong used $\mathrm{M}_{\max }=8.7 \pm 0.93$ for a repeat cycle of 2658 years for the northern part of Manila submergence zone (Nguyen Hong Phuong, 2015). Meanwhile, the results in this work are slightly higher than the results of the tectonic geological methods have been applied by other authors such as author Phan Trong Trinh results $\mathrm{M}_{\max }=8.6$ (according to the author) fault or $\mathrm{M}_{\max }=8.3$ (by fault length) (Phan Trong Trinh et al., 2011); Bui Cong Que evaluated $\mathrm{M}_{\max }=8.5$ (in terms of fault length) (Bui Cong Que, 2010); Or, according to a regular meeting held by the USGS in 2005, this confirmed that the potential for strong earthquakes exceeded 8.5 (Kirby et al., 2005). This difference may be due to the fact that the tectonic geological methods have evaluated $\mathrm{M}_{\max }$ through intermediate variables such as faults. Fault lengths based on fixed assumptions for all source areas fracture is a rectangle that is twice the width of the width; it is also possible that the field results do not fully reflect these parameters. In addi- 
tion, the probability result depends on the probability of expectation (the larger the probability, the smaller the $\mathrm{M}_{\max }$ result). Therefore, when evaluating $\mathrm{M}_{\max }$ for any given region, reference should be made to the results of both probabilistic and geological methods.

In spite of the similarity of these assessments, the results obtained in this work are more reliable because the calculations made using seismic data are purely logarithmic. Received by machine, the earthquake list was established on the basis of calibration and unification of data from different sources for a single magnitude torque. In addition, other probabilistic methods for evaluating $\mathrm{M}_{\max }$ over a very long period, several hundred years or several thousand years, but the results of the $\mathrm{M}_{\max }$ evaluation in this work are limited to periods. It should be noted, however, that during the data period of the study, although the highest density of earthquakes was observed in the eastern part of the East Sea, some of the strongest earthquakes with $\mathrm{M}_{\mathrm{w}} \geq 8.0$ occurred out in the southeast of the study area. Therefore, in order to confirm that the maximum earthquake magnitude $\mathrm{M}_{\max }=8.7$ is predicted for a specific part of the East Sea, it is still necessary to evaluate the maximum magnitude of the earthquake for the particular region of the zone. That is the direction that research should continue in the East Sea.

\section{Conclusions}

Based on seismic data collected from different sources, we have the following conclusion:

The seismic region of the East Sea between 1900 and 2017 is characterized by the magnitude 4.7. The earthquakes are mainly distributed in the earth's crust at the eastern and southeastern part of the study area.

Strong earthquake activity in the East Sea area shows that the cyclicality through each period. From 1900 to 2017, it has four stages of strong earthquake activity, each stage lasts nearly 30 years with particular characteristics. In each phase, there are 1-2 strong earthquakes with $\mathrm{M}_{\max } \geq 8.0$. The strong earthquakes with $\mathrm{M}_{\max } \geq 7.5$ occur according to the rule of repeatability of 3-5 years.

On the basis of the unified earthquake catalog in period 1917-2017 with $\mathrm{M}_{\mathrm{w}} \geq 5.0$, maximum magnitude values for the East Sea region has assessed by GEV method with several different predict periods $(20,40,60,80$, 100 years). With predict period 100 years, we have

$$
M_{\max }^{\text {predict }} \underset{\tau \rightarrow \infty}{=} \lim _{q} Q_{q}(\tau)=8.7 .
$$

This result is quite similar to previous research results. It proves that the results of previous studies are objective and the application of the GEV method to evaluating $\mathrm{M}_{\max }$ is feasible.

\section{Acknowledgments}

The authors would like to thank the support of the scientific research mission in 2018 NVCC12.01/18-18.

\section{References}

Bautista C.B., Bautista M.L.P., Oike K., Wu F.T., Punongbayan R.S., 2001. A new insight on the geometry of subducting slabs in northern Luzon, Philippines. Tectonophysics, 339, 279-310.

Bui Cong Que, et al., 2010. Seismic and tsunamis hazard in coastal Viet Nam. Natural Science and Technology Publishing House, 311p.

Bui Van Duan, Nguyen Cong Thang, Nguyen Van Vuong, Pham Dinh Nguyen, 2013. The magnitude of the largest possible earthquake in the Muong LaBac Yen fault zone. J. Sci. of the Earth, 35, 53-59 (in Vietnamese).

Cao Dinh Trieu, Pham Nam Hung, 2008. Deep-seated fault zone presents the risk of strong earthquakes in the East and South Vietnam Sea. Scientific Report of the First National Conference on Marine Geology, Ha Long, October, 9-10, 491-497.

Hsu Ya-Ju, Yu Shui Ben, Song Teh.-Ru Alex, Bacolcol Teresito, 2012. Plate coupling along the Manila subduction zone between Taiwan and northern Luzon. 
Vu Thi Hoan, et al./Vietnam Journal of Earth Sciences 40 (2018)

J. Asian Earth Sci., 51, 98-108.

$h t t p: / / w w w . i o c-$

tsuna-

mi.org/index.php?option=com_oe\&task=viewDocume ntRecord\&docID $=16478$.

http://www.jcomm.info/index.php?option=com_oevàtas $\mathrm{k}=$ viewDocumentRecordvafdocID $=16484$.

Kirby S., Geist E., Lee W.H., Scholl D., Blakely, R., October 2005. 660 Tsunami source characterization for western Pacific subduction 661 zones: a perliminary report. Report, USGS Tsunami Subduction 662 Source Working Group.

Le Huy Minh, Frederic Masson, Alain Bourdiilon, Patrick Lassudrie Duchesne, Rolland Fleury, Jyr-ching $\mathrm{Hu}, \mathrm{Vu}$ Tuan Hung, Le Truong Thanh, Nguyen Chien Thang, Nguyen Ha Thanh, 2014. GPS data continuously in Vietnam and Southeast Asia. J. Sci. of the Earth, 36, 1-13.

Le Van De, 1986. Outline of tectonics of the East Vietnam sea and adjacent areas. Proc. $1^{\text {st }}$ Conf. Geol. Indoch., Ho Chi Minh City, 397-404, Hanoi.

Ngo T.L., Tran V.P., 2013. Development of a new algorithm for the separation of seismic and anemone groups from the earthquake list to ensure the independence of events. Journal of Marine Science and Technology, Hanoi, 13(3A), 79-85.

Nguyen Dinh Xuyen., et al., 2007. Report on the implementation of the task "Earthquake scenarios for tsunamis in the South China Sea". Institute of Meteorology and Hydrology.

Nguyen Hong Phuong, 2015. Estimation of seismic hazard parameters for potential tsunami genic sources in the South China Sea region.

Nguyen Hong Phuong, 2001. Probabilistic Seismic Hazard Assessment Along the Southeastern Coast of Vietnam, Natural Hazards, 24, 53-74.

Nguyen Hong Phuong, 2004. Earthquake risk map of Vietnam and East Sea. J. Sci. of the Earth, 26, 97-111.

Nguyen Hong Phuong, Bui Cong Que, 2012. Investigation of earthquake tsunami sources, capable of affecting Vietnamese coast, Nat Hazards, 64, 311-327.

Nguyen Hong Phuong, Pham The Truyen, 2014. Probabilistic Seismic Hazard Assessment for the South
Central Vietnam. J. Sci. of the Earth, 36, 451-461.

Nguyen Van Luong, Bui Cong Que, Nguyen Van Duong, 2008. Tectonic stresses and modern movements in the crust of the Earth in the East Sea area, Journal of Marine Science and Technology, 46-52.

Nguyen Van Luong, Duong Quoc Hung, Bui Thi Thanh and Tong Duy Cuong, 2003. Characteristics of fault systems in the East Sea area. J. Sci. of the Earth., 25, 1-8 (in Vietnamese).

Nguyen Van Luong, et al., 2002. Result of establishment of the list of earthquake dynamics in the East Sea area, studies on geology and marine geophysics, VII, Hanoi.

Nguyen Van Luong, et al., 2008. Tectonic seismic and geodynamic features of the South China Sea, Proceedings of the 1st National Conference on Marine Geology and Sustainable Development, 910, Ha Long, 498-509.

Pham Van Thuc and Nguyen Thi Kim Thanh, 2004. Earthquake zone in the South China Sea and coastal areas. Journal of Geology, A series, 285, 11-12.

Pham Van Thuc, 2001, Characteristics of tsunamis in the East Sea region of Vietnam. TC and CNN, TI, 2, 52-64.

Phan Trong Trinh, Ngo Van Liem, Vy Quoc Hai, John Beavan, Nguyen Van Huong, Hoang Quang Vinh, Bui Van Thom, Nguyen Quang Xuyen, Nguyen Dang Tuc, Dinh Van Thuan, Nguyen Trong Tan, Nguyen Viet Thuan, Le Huy Minh, Bui Thi Thao. Nguyen Huy Thinh, Dinh Van The, Le Minh Tung, Tran Quoc Hung, Nguyen Viet Tien, 2010b. Modern tectonic movement in the East Sea and surrounding areas. Journal of Geology. Series A, 320, 9-10, Hanoi.

Phan Trong Trinh, 2006. The Tsunami and December 26, 2004 in the Indian Ocean: A Warning to Vietnam. Journal of Geology, Series A, 293, Hanoi.

Phan Trong Trinh, et al., 2010a. Research on the tectonic activity, modern tectonics and geodynamics of the South China Sea as a scientific basis for forecasting the types of catastrophe involved and proposed solutions prevent. KC.09.11/06-10. Institute of Geology, 446p. 
Vietnam Journal of Earth Sciences, 40(3), 240-252

Phan Trong Trinh, Nguyen Van Huong, Ngo Van Liem, Tran Dinh To, Vy Quoc Hai, Hoang Quang Vinh, Bui Van Thom, Nguyen Quang Xuyen, Nguyen Viet Thuan, Bui Thi Thao, 2011. Geological and geological hazards in Vietnam's sea and nearby. J. Sci. of the Earth, 33, 443-456.

Pisarenko V.F., Sornette A., Sornette D. and Rodkin M.V, 2008. New approach to the Characterization of $\mathrm{M}_{\max }$ and of the Tail of the Distribution of Earthquake Magnitudes. Pure and Applied Geophysics, 165, 847-888.

Pisarenko V.F, Sornette D. and Rodkin M.V., 2010. Distribution of maximum Earthquake magnitudes in future time intervals: application to the seismicity of Japan (1923-2007). EPS (Earth, Planets and Space), 62, 567-578.

Pisarenko V.F., Rodkin M.V, and Rukavishnikova T.A., 2014. Estimation of the Probability of Strongest Seismic Disasters Based on the Extreme Value Theory. Physics of the Solid Earth, 50(3), 311-324.
Pisarenko V.F., Rodkin M.V. and et al., 2012. New general quantile approach to the seismic rick assessment application to the Vietnam region. //Proceedings of the International Conference on "Geophysics - Cooperation and Sustainable Development." Science and Technology Publishing House. Hanoi, 161-167.

$\mathrm{Vu}$ Thanh $\mathrm{Ca}, 2008$. Report on the project to build a map of tsunami warning for coastal areas of Vietnam. Institute of Hydrometeorology and Environment - Ministry of Natural Resources and Environment.

Yingchun Liu, Angela Santos, Shuo M. Wang, Yaolin Sh, Hailing Liu, David A. Yuen, 2007. Tsunami hazards along Chinese coast from potential earthquakes in the South China Sea. Phys. Earth Planet. Interiors, 163, 233-244.

Zhiguo Xu, 2015. Seismicity and Focal mechanisms in the South China Sea Region and its Tectonic Significances. 